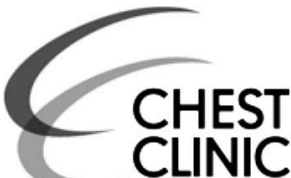

Additional material is published online only. To view please visit the journal online (http://dx.doi.org/10.1136/ thoraxinl-2017-210210).

Department of ICU, 'Papageorgiou' General Hospital, Thessaloniki, Greece

\section{Correspondence to} Dr Savvoula Savvidou, 'Papageorgiou' General Hospital, Ring Road N.EfkarpiaThessaloniki, Thessaloniki 56402, Greece; ssavidou@med. auth.gr

Received 7 March 2017 Revised 20 May 2017 Accepted 29 May 2017 Published Online First 25 July 2017

\title{
A central venous catheter that revealed a vascular paradox
}

\author{
Savvoula Savvidou, Entela Koco, Matthew Tsagourias, Dimitrios Matamis
}

\section{CLINICAL PRESENTATION}

A 60-year-old man with insignificant past medical history, was admitted to the intensive care unit with acute respiratory failure following community-acquired pneumonia. On admission, he was haemodynamically stable in sinus rhythm, febrile and neurologically intact with no focal neurological findings. Under mechanical ventilation, the ratio of arterial oxygen $\left(\mathrm{PaO}_{2}\right)$ to fractional inspired oxygen concentration $\left(\mathrm{FiO}_{2}\right)$ was 100 . An antibiotic regime of ceftriaxone plus moxifloxacin was administered.

On day 6, a 3-lumen central venous catheter (CVC) (Arrow, $7 \mathrm{Fr} \times 20 \mathrm{~cm}$, polyurethane radiopaque) was easily inserted into his left internal jugular vein using anatomical landmarks. Aspiration of blood from the distal tip of the catheter confirmed its intravascular placement; however, the sample's bright red appearance strongly suggested it was 'arterial' in origin. Bedside B-mode ultrasonography excluded false cannulation of the carotid artery. Furthermore, connection of the CVC with a pressure transducer produced a venous waveform with low pressure. Blood gas analysis of the CVC sample returned a $\mathrm{PaO}_{2}$ value of $49 \mathrm{kPa}(371 \mathrm{mmHg})$, whereas the $\mathrm{PaO}_{2}$ simultaneously measured in a sample from the arterial line was $11 \mathrm{kPa}(80 \mathrm{mmHg})$. The CVC remained in position but not in use; a post-procedural chest X-ray was obtained (figure 1).

\section{QUESTION}

Having evaluated both the chest X-ray and the unexpectedly high partial oxygen concentration $\left(\mathrm{PO}_{2}\right)$, we concluded that the catheter was misplaced. Given this information, where is the tip of the CVC most likely located?

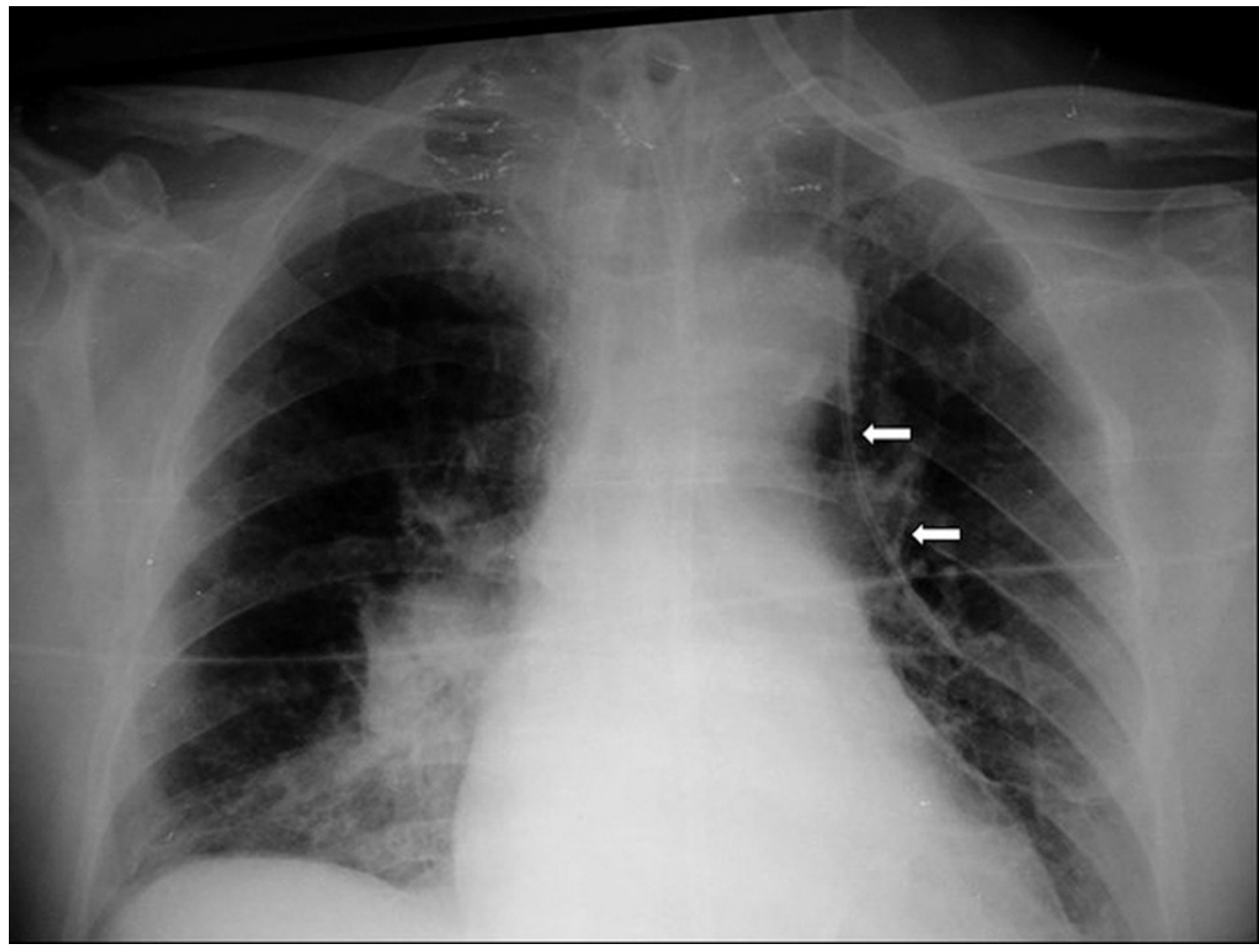

Figure 1 Anteroposterior chest radiograph showing a vertical route of catheter (white arrows) beyond the aortic knob, on the left side of the mediastinum, that seems to 'wedge' into the left lung. 

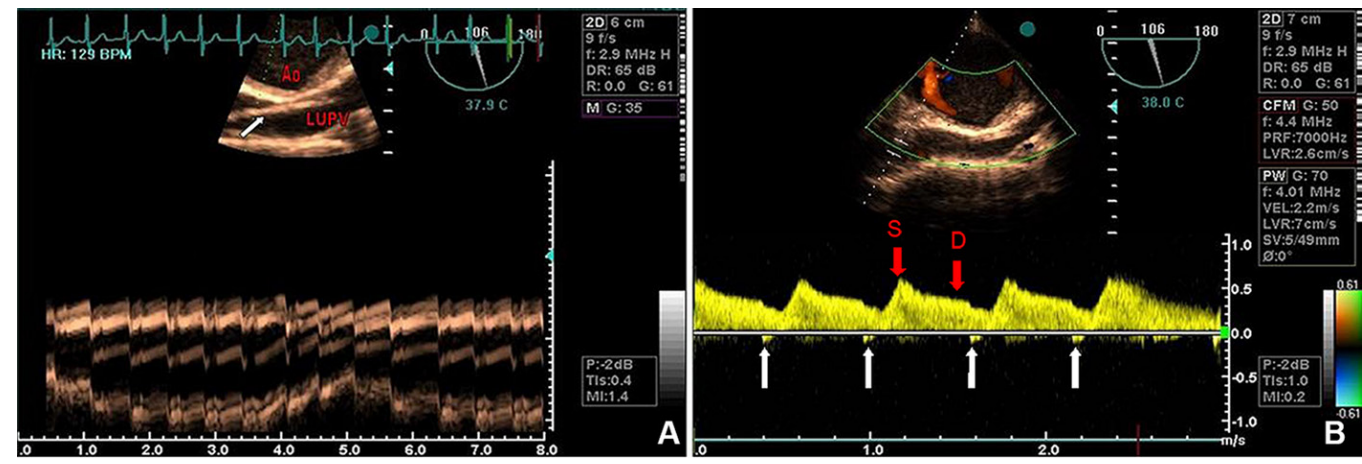

Figure 2 Trans-oesophageal echocardiography of the left upper pulmonary vein (LUPV): (A) The B-mode demonstrates the catheter (white arrow) inside the LUPV behind the aorta (Ao) and cardiac vibrations of the catheter in the M-mode (lower panel). (B) Pulse-wave Doppler of the LUPV demonstrates a typical pulmonary vein flow pattern during the systolic (S) and diastolic (D) phase (red arrows), and minimal sequential atrial-reversal flow waves (white arrows).

\section{ANSWER}

The paradox in this case was the extremely high $\mathrm{PO}_{2}$ level in a sample drawn from a low-pressure vessel, which far exceeded the $\mathrm{PO}_{2}$ level in the arterial blood sample. That led us to suspect a possible cannulation of a pulmonary vein.

A trans-oesophageal echocardiography was first performed; it confirmed the position of the catheter within the left upper pulmonary vein (figure 2) and ruled out any cardiac dysfunction, right-sided chamber enlargement, valvular disease or pulmonary hypertension. Central injection of agitated saline did not suggest the presence of patent foramen ovale.

Subsequently, the patient was transferred to the catheterisation lab, and selective angiography via the right femoral vein (figure 3) clearly demonstrated communication between the left upper pulmonary vein and the innominate vein (see online supplementary videos). Sequential blood gas evaluations of $\mathrm{PO}_{2}$ confirmed the presence of an abnormal left-to-right shunt, attributed to this atypical communication, and the catheter was safely removed thereafter.

\section{DISCUSSION}

This is a case of partial anomalous pulmonary vein connection (PAPVC). PAPVC is a rare $(0.4-0.7 \%$ of postmortem examinations) congenital defect in which one or more - but not all - of the pulmonary veins fail to drain into the left atrium. ${ }^{1-3}$ It is an abnormal anatomic variant explained by the persistence of embryonical anastomoses between systemic veins and the pulmonary venous plexus. ${ }^{1}$ Only a minority of these cases (10-18.2\%) affect the left lung; on the right, abnormal pulmonary veins usually coexist with atrial septal or other cardiac defects. ${ }^{3}$

Observational cohort studies of such patient series found that PAPVC's manifestations depend on the magnitude of the leftto-right shunt and the co-existence of other defects. ${ }^{3-5}$ Symptoms and signs may arise from right ventricular dysfunction and pulmonary hypertension. ${ }^{3-5}$ Single left abnormal pulmonary vein connections, similar to our case presentation, may go undetected and only be discovered accidentally. ${ }^{34}$ However, physicians, especially intensivists, should be aware of this rare anatomical anomaly that requires a high index of clinical suspicion to diagnose.

Acknowledgements We would like to thank cardiologists Dr L Mosialos and Dr V Sachpekidis for their invaluable help.

Contributors All authors contributed equally to the preparation of the manuscript; SS and EK reviewed the literature and planned the report, MT conducted the diagnostic investigation and provided the supporting images, DM with SS were responsible for the writing and the overall content as guarantors.

Competing interests None declared.

\section{Patient consent Obtained.}

Provenance and peer review Not commissioned; externally peer reviewed.

(c) Article author(s) (or their employer(s) unless otherwise stated in the text of the article) 2017. All rights reserved. No commercial use is permitted unless otherwise expressly granted.

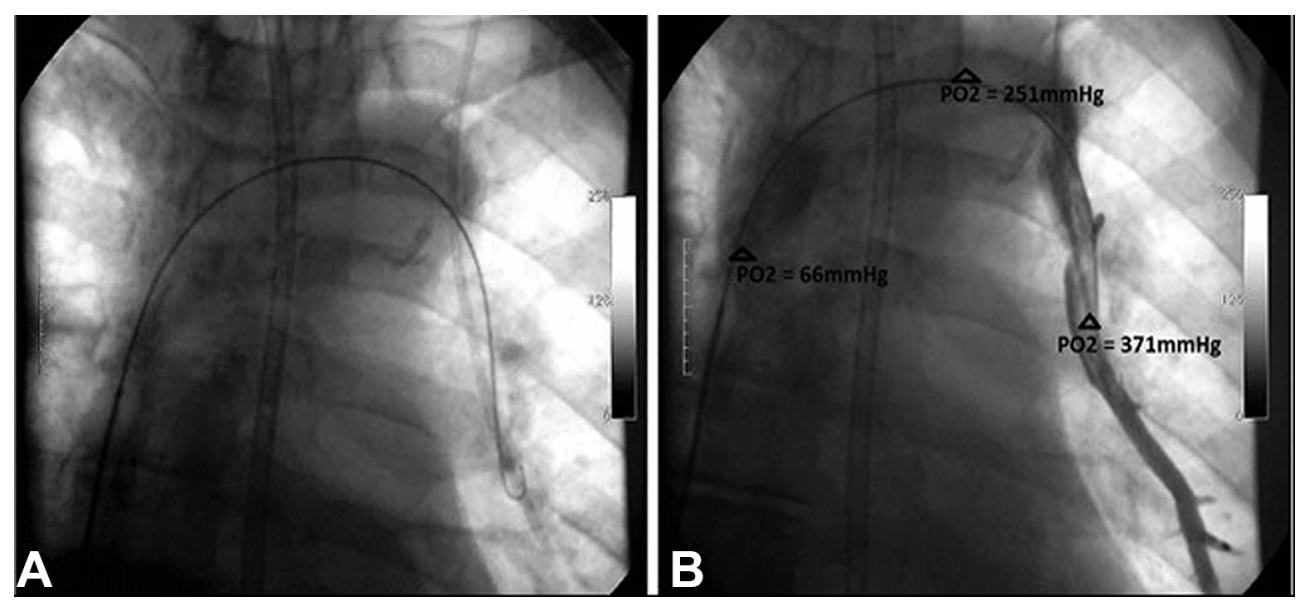

Figure 3 Selective angiography: (A) Radioscopic catheterisation of the vessel with the central vein catheter remaining inside. (B) Sequential blood samples drawn from the distal tip of the central vein catheter; left upper pulmonary vein with $\mathrm{PO}_{2}=371 \mathrm{mmHg}(49 \mathrm{kPa})$, the innominate with left-toright shunt, $\mathrm{PO}_{2}=251 \mathrm{mmHg}(33 \mathrm{kPa})$ and the superior vena cava with mixed venous, $\mathrm{PO}_{2}=66 \mathrm{mmHg}(9 \mathrm{kPa})$. 


\section{REFERENCES}

1 Sobrinho G, Salcher J. Partial anomalous pulmonary vein drainage of the left lower lobe: incidental diagnostic after central venous cannulation. Crit Care Med 2003;31:1271-2.

2 Almeda FQ, Barkatullah S, Nathan S, et al. Partial anomalous pulmonary venous drainage of the superior left pulmonary vein into the innominate vein resulting in right ventricular failure. Am J Med 2002;113:168-9.
3 Javangula K, Cole J, Cross M, et al. An unusual manifestation of left partial anomalous pulmonary venous connection. Interact Cardiovasc Thorac Surg 2010;11:846-7.

4 Ammash NM, Seward JB, Warnes CA, et al. Partial anomalous pulmonary venous connection: diagnosis by transesophageal echocardiography. J Am Coll Cardiol 1997:29:1351-8.

5 ElBardissi AW, Dearani JA, Suri RM, et al. Left-sided partial anomalous pulmonary venous connections. Ann Thorac Surg 2008;85:1007-14. 